\title{
Demonstrating a conceptual model for multispecies landscape pattern indices in landscape conservation
}

\author{
Nathan M. Tarr $\mathbb{B}$
}

Received: 29 November 2018/Accepted: 1 August 2019/Published online: 6 September 2019

(C) The Author(s) 2019

\begin{abstract}
Context Our ability to understand the implications of prescriptions for landscape change (i.e., conservation actions) is constrained by the scopes of spatial pattern indices employed to describe landscapes. Most indices are suited for use with a single species or habitat, but the consequences of conservation actions are inherently multispecies. Hence, indices that incorporate information for multiple species are desirable.

Objectives I describe a conceptual model for multispecies spatial pattern indices that incorporates species-specific habitat definitions and scales of landscape effects. I explore its utility for conservation planning and present insights and suggestions for its application.

Methods The conceptual model employs habitat maps and estimates of species' scales of effect for habitat amount within landscapes surrounding sites. I present three indices rooted in the model: cumulative habitat amount, fragmented species count (FSC), and
\end{abstract}

Electronic supplementary material The online version of this article (https://doi.org/10.1007/s10980-019-00888-7) contains supplementary material, which is available to authorized users.

N. M. Tarr $(\bowtie)$

USGS North Carolina Cooperative Fish and Wildlife

Research Unit, Department of Applied Ecology, North

Carolina State University, Campus Box 7617, Raleigh,

NC 27695, USA

e-mail: nmtarr@ncsu.edu fragmented species-habitat count (FSHC). Comparisons of FSC and FSHC values at individual sites can reveal areas of high importance for protection as well as a measure of conservation design problem complexity. I demonstrate application of the indices for 40 species within a study area in the northwestern U.S.

Results The indices provided a visualization of spatial patterns in multispecies habitat fragmentation across the study region, revealing areas with relatively high levels of habitat fragmentation and sites where habitat configuration is of high importance for the species analyzed.

Conclusions The conceptual model provides descriptions of landscapes that can provide important context for conservation actions. Implementation may warrant further development, exploration of sensitivities, or case-specific refinements.

Keywords Spatial pattern indices - Landscape conservation - Scale of effect - Multispecies approach . Landscape planning - Ecological restoration . Biodiversity $\cdot$ Habitat fragmentation

\section{Introduction}

Habitat fragmentation has been considered a primary threat to biodiversity because of widespread 
anthropogenic land use change and what are believed by many to be negative relationships between the spatial patterns of fragmented landscapes and species that inhabit them (Fardila et al. 2017). On the basis of those relationships, some conservationists have assessed the implications of historical landscape changes on biodiversity and prescribed changes that would alter the spatial configuration of habitat to increase connectivity and mitigate fragmentation effects (Fardila et al. 2017). Examples of such landscape conservation actions include conservation corridors (Vos et al. 2002) and strategically placed protected areas (Belote et al. 2016) or ecological restorations (Huxel and Hastings 1999).

Efforts to understand the ecological implications of landscape changes have largely focused on single species or, alternately, on animal assemblages that are associated with a single natural land cover type (Lindenmayer and Fischer 2006; Fardila et al. 2017). Views of landscape patterns that are limited to single species or species assemblages have been foundational to landscape ecology, but they provide narrow contexts for understanding the consequences of conservation actions because landscape changes affect many species with unique ecologies that can be at odds with each other (Lindenmayer and Fischer 2006). Those narrow contexts create risks of unforeseen or unknown consequences of conservation actions. Surrogate species, such as umbrellas and indicators, are often used in landscape assessments in attempt to account for multiple species by applying knowledge about single-species or single-species methods, but the utility of the surrogate species approach has been questioned because it assumes similarity among the ecologies of species that each surrogate represents, which may not exist (Noon et al. 2009). Hence, multispecies approaches are desirable because, in many cases, they could provide an opportunity to broaden the scope of study and provide a more complete understanding of the consequences of observed or expected landscape changes.

The use of multispecies indices could broaden our views of landscape patterns and the consequences of conservation actions by incorporating two key ecological realities. First, each species responds to landscape conditions and features in a unique way that forms a distinct definition of what is habitat for that species (Table 1; Hall et al. 1997; Lindenmayer and Fischer 2006). That definition can differ from a common use of the term "habitat" to refer to an individual type of vegetative community, such as "forest habitat" (Lindenmayer and Fischer 2006; Fahrig 2013). Many methods for describing and mapping species' habitats exist, but all represent single or sets of biotic and/or abiotic (continuous or categorical) data layers as spatial distributions or predicted probabilities of habitat occurrence. Probabilistic habitat maps are often continuous but can be presented in binary terms via thresholding for assessment and planning applications (Franklin 2009). Binary habitat maps are often patch-matrix models of habitat patches within non-habitat matrix (Frazier and Kedron 2017). Importantly, the spatial distributions of habitat for different species can be partially, completely, or non-overlapping within the landscapes where they co-occur, so a given species' distribution may not be nested within or complementary to another's. Habitat maps have been created for use in regional and national conservation projects including the USGS Gap Analysis Project (McKerrow et al. 2018), and prospects are high for the development of more maps given the recent interest in methods for mapping species' distributions (Araújo et al. 2019).

A second important concept that multispecies indices could incorporate is that species' individual abilities and propensities to move through space influence the scales at which they experience landscapes (Addicott et al. 1987), and therefore, the distances at which individuals and populations are influenced by the landscape structure surrounding them. Modelers of species occurrence, population vital rates, and population persistence have incorporated landscape structure by calculating measures of spatial pattern (i.e., landscape predictors) within areas around sites (Gustafson 1998; Betts et al. 2006; Martin and Fahrig 2012; Fardila et al. 2017). Models have shown that, for a single species, the distances at which landscape effects are measurable or consequential, termed "scales of effect" (Table 1), likely vary among indices (Jackson and Fahrig 2012) and processes of interest (Addicott et al. 1987; Martin and Fahrig 2012). Additionally, scale domains may exist for a particular response by a species to a landscape characteristic (Wiens 1989). While it is unlikely that scales of effect will be documented for all species and spatial pattern indices, the burgeoning field of movement ecology holds promise for documenting the underlying movement abilities of individual species and, thus, 
Table 1 Definitions of key terms

\begin{tabular}{|c|c|}
\hline Term & Definition \\
\hline Habitat & $\begin{array}{l}\text { Resources and conditions in an area that produce occupancy by a species (Hall et al. 1997); } \\
\text { species-specific }\end{array}$ \\
\hline Scale of effect & $\begin{array}{l}\text { The spatial extent at which a landscape effect is measurable or consequential for a species (Jackson } \\
\text { and Fahrig 2012) }\end{array}$ \\
\hline Neighborhood & $\begin{array}{l}\text { The area surrounding a site within which landscape structure is consequential for a species; a } \\
\text { circular area with radius equal to the scale of effect for a particular measure of landscape } \\
\text { structure; species-specific }\end{array}$ \\
\hline Fragmentation threshold & $\begin{array}{l}\text { A habitat amount within the landscape around a cell above which habitat patch configuration is } \\
\text { unimportant and below which the habitat is considered fragmented (Andrén 1994; Villard and } \\
\text { Metzger 2014) }\end{array}$ \\
\hline Region of fragmentation & A subregion of a study area where habitat is fragmented for a species \\
\hline Fragmented species & A species whose habitat is fragmented within some region of interest, such as a neighborhood \\
\hline $\begin{array}{l}\text { Cumulative habitat amount } \\
\text { (CHA) }\end{array}$ & $\begin{array}{l}\text { A multispecies sum of habitat amounts within the species-specific neighborhoods surrounding a } \\
\text { focal site }\end{array}$ \\
\hline $\begin{array}{l}\text { Fragmented species count } \\
\text { (FSC) }\end{array}$ & The number of species for which a site is located within a region of fragmentation \\
\hline $\begin{array}{l}\text { Fragmented species-habitat } \\
\text { count (FSHC) }\end{array}$ & $\begin{array}{l}\text { The number of species for which a site is located within a region of fragmentation and is habitat; } \\
\text { the number of fragmented species that may inhabit a particular site }\end{array}$ \\
\hline
\end{tabular}

the scales at which they interact with landscapes (Fardila et al. 2017).

With habitat maps and scales of effect identified or estimated for individual species in a multispecies landscape assessment, planning, or characterization exercise, choices arise with regards to what to quantify across the landscape in order to characterize the landscapes surrounding sites, individuals, or populations. Numerous options are available (McGarigal 2015), but landscape composition and patch configuration are the primary components of spatial heterogeneity and structural connectivity (Gustafson 1998) and, thus, are the key landscape patterns to quantify. Composition is often measured as the proportion of a landscape that is habitat for a species (i.e., "habitat amount"), whereas a variety of pattern indices, such as patch size and edge length are available to characterize the configuration of patches within landscapes (Gustafson 1998; Betts et al. 2006; McGarigal 2015).

The relationships between composition and configuration indices can be complex, because landscape composition and configuration are linked (Fahrig 1997, 2003). That is, the arrangement of habitat changes with habitat loss (Didham et al. 2011). Additionally, the relationships between the influences of habitat amount and configuration on local processes are complex: the configuration of habitat is thought to be less important when there is more habitat in a landscape (Andrén 1994; Gustafson 1998). Simulations and empirical studies have suggested that thresholds in proportion of habitat likely exist above which configuration is unimportant (Andrén 1994; Fahrig 1997). Such thresholds have been called "fragmentation thresholds" (Table 1). Villard and Metzger (2014) presented a conceptual framework in which configuration is only important within a range of intermediate levels of habitat amount that is bounded by an extinction threshold, below which the amount of habitat is insufficient for population persistence, and a fragmentation threshold, above which configuration is unimportant. It is worth noting that the importance of habitat amount versus configuration has been debated. Fahrig (2013) presented an alternative view on the importance of habitat configuration, arguing that observed configuration effects are attributable to habitat amount (i.e., the "sample area effect"), but this view is somewhat controversial (Didham et al. 2011; Haddad et al. 2017).

The importance of habitat configuration to local populations or individuals is relevant to conservation planning because the design challenges associated with a prospective conservation action could be more or less complex depending on the importance of habitat configuration for the affected species. 
Complexity will arise in a design exercise when species with dissimilar habitat requirements cooccur in the affected landscape, because the cooccurrence of such species might present tradeoffs whereby accommodating one species at a site causes the exclusion of another. In such cases, if habitat configuration is unimportant in the affected areas, then the tradeoff could be handled by reconfiguring habitat in the landscape without affecting the amount of habitat for either species. Conversely, if habitat configuration is important for both species, then options for aiding one species without harming the other could become either zero-sum, severely reduced, or difficult to identify.

In the sections that follow, I outline a conceptual model for multispecies landscape pattern indices that incorporates species' unique habitat definitions and scales of effect, and I demonstrate its utility for landscape conservation planning. I present three indices based upon the conceptual model and discuss the potential for their use to broaden characterizations of spatial patterns in biodiversity and habitat fragmentation. I also discuss their potential value for conservation planning under the assumption that habitat patch configuration has little importance where habitat is abundant. Finally, I discuss potential extensions, important limitations, and likely sensitivities to errors and parameterization.

\section{Model description and demonstration}

In the model for multispecies landscape pattern indices presented here, the spatial patterns of habitat are quantified and/or categorized throughout landscapes for individual species. Those species-specific characterizations of spatial patterns are then aggregated to produce multispecies indices. The three indices that I present are based upon measures of habitat amount, although other landscape pattern indices could be used instead, including ones that reflect patch configuration rather than composition.

\section{Example multispecies landscape pattern indices}

Cumulative habitat amount (CHA) - $\mathrm{CHA}$ is the sum of individual species' habitat amounts surrounding a focal site. All study species for which habitat exists within their scale of effect distance of the site are included, so CHA represents a total multispecies habitat amount for the landscape centered around a site (Table 1). However, an important aspect of CHA is that the landscape around the site that is assessed is actually an aggregation of species-specific landscapes of potentially different sizes. Those species-specific landscapes which are centered around the focal site are assigned a radius according to each species' scale of effect. Hereafter, I refer to such areas as "neighborhoods."

To calculate CHA, habitat amount is first quantified within the neighborhoods of all grid cells throughout each species' habitat map. Habitat amount is quantified as the proportion of each neighborhood that is habitat (Fig. 1A). That step produces habitat amount maps for each species with values for each cell (Fig. 1B), and habitat amount values from each species are then summed at each cell. CHA maps depict spatial patterns in landscape composition for multiple species and could be informative in assessment or planning exercises that wish to account for landscape effects on observed species richness or the value of a specific site. In some applications, it may be valuable to use mean or median habitat amount instead of total habitat amount.

Fragmented species count (FSC)-FSC is the number of species for which a focal site is located where the habitat is considered fragmented. Hereafter, I refer to such portions of a study area as "regions of fragmentation" for a species (Table 1). Like CHA, FSC reflects information at the landscape level because it is based upon assessments of whether a site is located within particular regions of the study area. However, as with CHA, the landscape that is assessed for each cell is multispecies and defined in part by the study species' diverse scales of effect and spatial distributions of habitat. Thus, the dimensions of the landscapes being characterized around cells are likely to vary across regions with heterogeneous compositions or features.

To calculate FSC, regions of fragmentation are first identified for each species. One approach to mapping regions of fragmentation is by applying a fragmentation threshold (Table 1) to a proportion habitat map (Fig. 1B). In that approach, the continuous values of the proportion habitat map are converted to binary values with the fragmentation threshold such that cells centered in neighborhoods where habitat is fragmented are assigned the foreground value, thus identifying cells within regions of fragmentation 

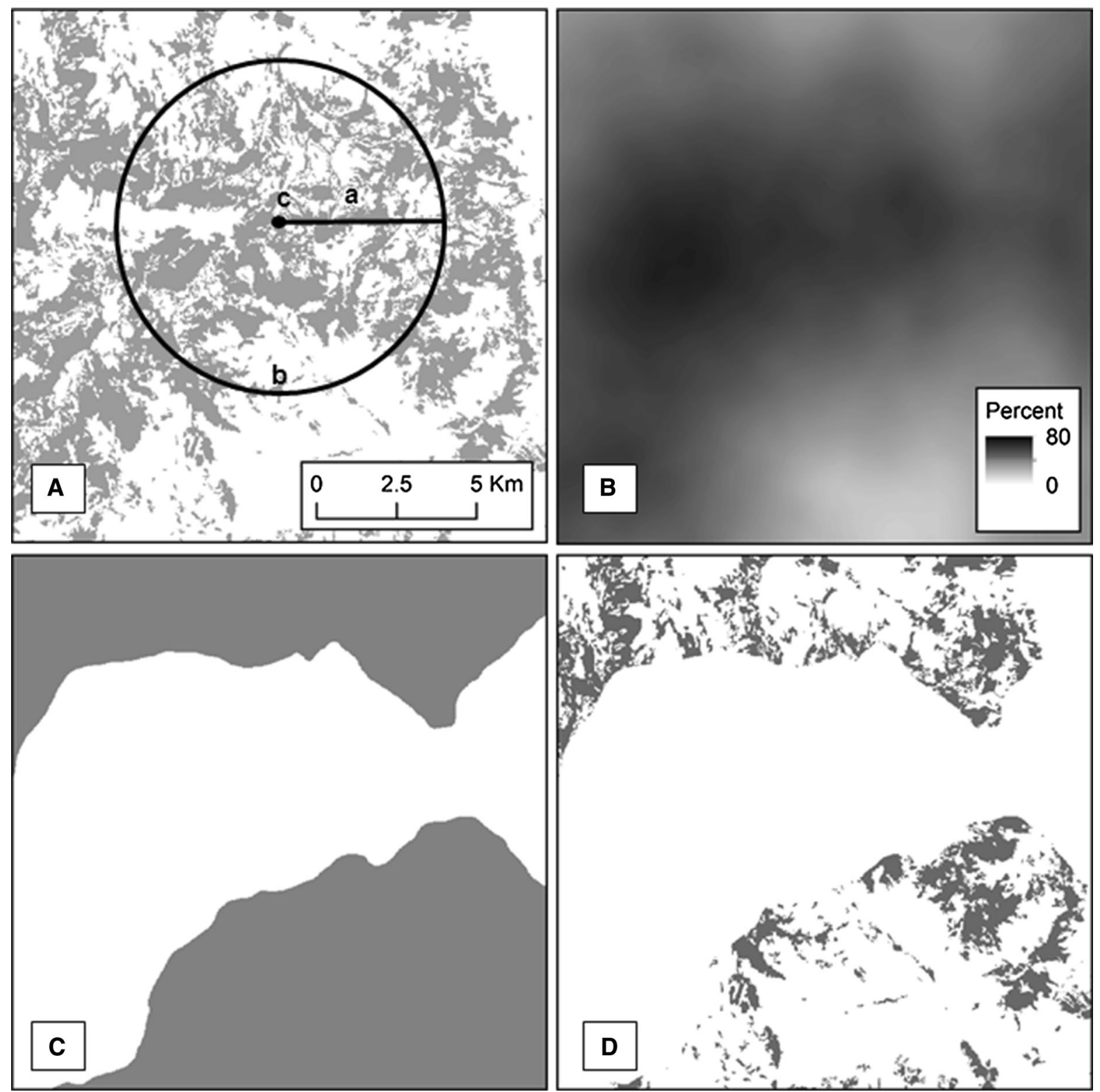

Fig. 1 Example of the single-species calculations used for the multispecies indices. The map extents are a portion of the demonstration study area shown in Fig. 2. A A habitat map for a single species, shown in gray, with a scale of effect of $5 \mathrm{~km}$ (a) for habitat amount and a neighborhood (the area within circle b) superimposed around one grid cell (focal site at point c). A neighborhood exists for each grid cell in the map. B A habitat amount map in which grid cell values reflect the percentage of the area that is habitat within the neighborhood surrounding the

(Fig. 1C). Next, the region of fragmentation maps of all species can be summed to produce an FSC value for each cell. FSC maps incorporate several types of cell. C A region of fragmentation map created by assigning grid cells from the percent habitat map in (B) with values below a fragmentation threshold (50\%) to the foreground value (shown in gray). D A fragmented habitat map created by intersecting the habitat map in (A) with the region of fragmentation map (C). Multispecies indices are calculated by summing all species' habitat amount maps for CHA, regions of fragmentation maps for FSC, or fragmented habitat maps for FSHC

information: spatial patterns of species richness, spatial distributions of species' habitat, a measure of landscape structure (i.e., habitat amount), species- 
specific scales of effect, and a fragmentation threshold. FSC maps exclude areas not within the scale of effect distance of any habitat and where habitat is not considered fragmented for any species.

Fragmented species-habitat count (FSHC)—FSHC is the number of species for which a focal site is habitat that is located within a region of fragmentation (Table 1). The calculation of FSHC is identical to that of FSC, but with an added step of intersecting the region of fragmentation maps of each species (Fig. 1C) with their respective habitat maps (Fig. 1A) in order to identify habitat grid cells that are located within regions of the study area where habitat is fragmented for the species (Fig. 1D). The resulting maps of fragmented habitat for each species are summed for FSHC, as opposed to the region of fragmentation maps that are summed for FSC. Thus, this index incorporates the same information as FSC but additionally excludes non-habitat for each species. FSHC maps depicts spatial patterns in the number of fragmented species that may inhabit sites.

Study area and data

For demonstration of the calculation and application of the indices, I selected a $29,706.50 \mathrm{~km}^{2}$ study area in Washington State, USA that included a variety of natural features including mountains, rivers, and large water bodies, as well as agricultural areas and cities of various densities (Fig. 2a; Supplements 1 and 2). I extracted habitat maps within this area from the Gap Analysis Project's (GAP) 2001 national habitat maps (USGS-GAP 2018). GAP habitat maps were built with a deductive modeling method whereby biologists reviewed scientific literature and expert opinion on individual species habitat associations and entered that information into a wildlife-habitat relationship database (McKerrow et al. 2018). The database was queried and applied to spatial datasets such as GAP Land Cover, elevation, distance to water, forest-open edge, and forest interior to create seasonal maps of suitable habitat for survival or reproduction. I reclassified the seasonal maps to binary maps of summer habitat for the demonstration. The spatial resolution of GAP habitat maps is $30 \mathrm{~m} \times 30 \mathrm{~m}$.

Scales of effect for habitat amount are unknown for most species, but I used NatureServe's separation distances as approximations (NatureServe 2018; Supplement 3). Those data are estimates of distances at which patches of habitat should be considered functionally separated for individual species and were based on Natural Heritage Program biologists' reviews of information on species' mobility and dispersal behaviors.

Index calculation

I calculated the multispecies indices with the GAP habitat maps and proxies for scales of effect from NatureServe for 40 species. I randomly selected study species from a list of all terrestrial vertebrate species in the study area for which separation distances were available. In the GAP data, some habitat model parameters, such as stream buffers, are more common among some taxa than others, so I included 10 each of birds, amphibians, reptiles, and mammals in order to equalize the influences of inter-taxa similarities.

Like scales of effect, fragmentation thresholds are likely to vary among species and are largely unknown. However, values in the range of 10-50\% have been reported or suggested (Andrén 1994; Fahrig 1997; Flather et al. 2002; Freemark et al. 2002; Noon and Dale 2002; Villard and Metzger 2014). For this demonstration, I selected $50 \%$ to be conservative in what I ruled out as non-fragmented. Geoprocessing steps for the calculation of CHA, FSC, and FSHC maps were scripted in Python 2.7 (Python Software Foundation 2010) with the arcpy geoprocessing package from ArcGIS Desktop 10.4.1 (ESRI 2016) and Pandas 0.23.0 (McKinney and PyData Development Team 2018).

With the GAP habitat maps, I created habitat amount maps (Fig. 1b) for each species by calculating the percentage of the neighborhood around each cell that was habitat. Neighborhoods were defined as circles with radius length equal to the separation distances for the species (Fig. 1a). Summing the habitat amount maps of all 40 species produced CHA values that ranged from 97.01 to 1339.52; indicating unevenness in landscape composition across the landscape for the species examined (Fig. 2b). Areas with high and low habitat amounts occurred in areas with and without urban, suburban, or exurban developments. Low multispecies habitat amounts occurred atop Mt. Rainier and at large lakes, bays, and sounds near Seattle, WA.

There was also unevenness in FSC, which I calculated by first reclassifying habitat amount maps 

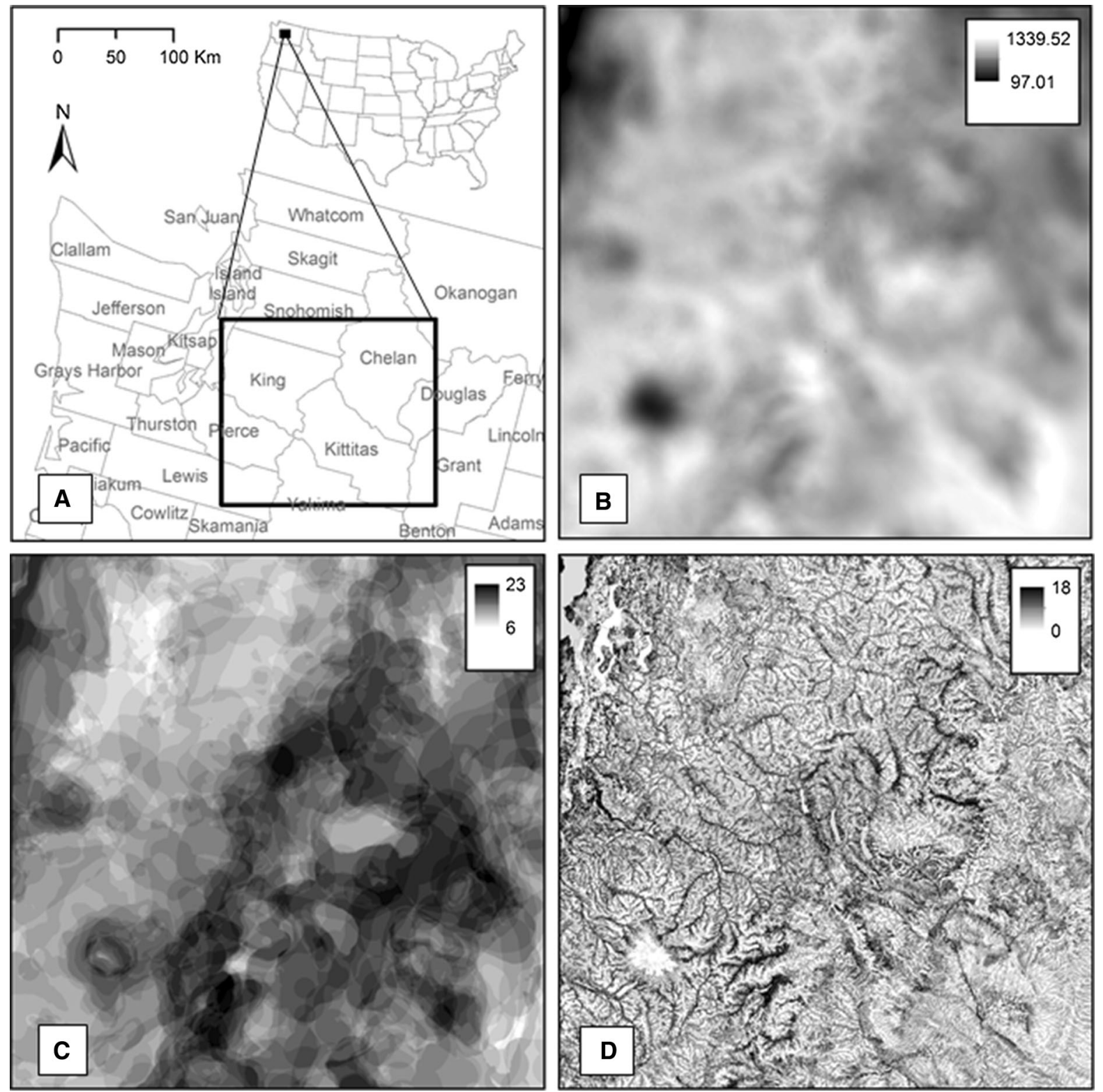

Fig. 2 Maps of multispecies landscape pattern index values derived from 40 species habitat maps: a the study region in Washington, USA, b cumulative habitat amount (CHA), c fragmented species count (FSC), and d fragmented species-

for each species according to the fragmentation threshold $(50 \%)$ and then summing the resulting region of fragmentation maps (Fig. 1c). The maximum possible value was 40 because 40 species were included in the analysis, but values ranged from 6 to 23 species. The median FSC value was 14 species, the 5th percentile was 9 species, and values above 20 were in

habitat count (FSHC). Legend units for (c) and (d) are number of species and summed proportions of habitat for $(\mathbf{b})$. The basemap of Fig. 4c can be used as a reference for landmarks and landforms in (b-d) because the map extents are identical

the 95th percentile. Under the assumption that configuration is of low importance in areas where habitat is not fragmented, unevenness in FSC indicated that the number of species that may be sensitive to the configuration of landscape features and land cover types is also unevenly distributed across the region. FSC values were relatively high in some coastal and 
mountain areas but areas with relatively low FSC occurred throughout the study region (Fig. 2c). In a landscape planning or assessment context, this pattern means that landscape changes in coastal and mountain areas could be consequential for more species than in areas with low FSC (Fig. 2c), which indicates greater complexity in landscape conservation questions at coastal and montane locations.

I calculated FSHC by summing the fragmented habitat maps (Fig. 1d) of all species. FSHC values ranged from 0 to 18 species with a median value of two species, which indicated that most grid cells were habitat for very few species for which habitat was fragmented around the cell. The 95th quantile was seven species and the value 1 was in the 25 th percentile. FSHC values appeared to be most heavily influenced by topography. Low FSHC values occurred throughout the study region on ridges, mountain peaks, large bodies of water, and other upland areas. Many of the highest FSHC values occurred along small streams, shorelines, and in areas dominated by human land uses such as roads, agricultural fields, and urban or suburban development (Fig. 2d).

Value for describing spatial patterns in biodiversity

CHA, FSC, and FSHC summarize information about landscapes around grid cells, such that map values describe relative patterns of fragmentation coarsely and aggregately for many species. One use of this information is in identifying general areas where fragmentation is relatively high and low (hereafter, fragmentation "hotspots" and "coldspots" respectively). Examining such locations in relation to the landscape features and conditions underlying them, would reveal the landscape conditions in which relatively high fragmentation levels can occur. For example, the occurrence and magnitude of high fragmentation levels in undeveloped landscapes or along ecotones could be explored. Examining fragmentation in relation to other descriptors, such as species richness or diversity (alpha and beta), would also broaden our understanding of spatial patterns in biodiversity by revealing fundamental correlations and dependencies between landscape heterogeneity and biodiversity that may not have been previously examined. That broader understanding would be possible because species-specific delineations of habitat provide species-specific representations of habitat amount and patchiness.

Applications to landscape conservation

The utilities of the indices for conservation are twofold. The new depictions of spatial patterns alone could improve the scopes of and contexts for assessments and prescriptions of landscape change, especially if used in concert with species richness maps and rarity, vulnerability, or priority weights for each species. Further utility could come from interpreting the maps while acknowledging the importance of landscape structure for wildlife: individuals and local populations respond to landscape structure in addition to site conditions (Cushman and McGarigal 2004; Fahrig 2013) and that response plays out from relationships between spatial heterogeneity within the surrounding landscape and processes such as immigration; emigration; reproduction, and survival at the site (Fahrig 1997). Many believe that sites within less fragmented landscapes have better chances of population persistence (Fardila et al. 2017; but see Fahrig 2003, 2013), and such a relationship supports a case for in-depth assessments of areas with low CHA or high FSC values (i.e., areas with many fragmented species) and interpretation of lower levels of CHA or higher levels of FSHC as potentially worse contexts for the persistence of populations at focal sites. Indepth assessments would involve investigating the importance of sites to the fragmented species as well as their responses to habitat configuration.

A second utility for conservation comes from comparing FSC and FSHC values at each site (i.e., grid cell) in a study area because they reflect information from different scales: landscapes and sites (Fig. 3). Exploring the parameter space between these two indices reveals further implications for conservation actions under the assumption that patch configuration is of low importance in non-fragmented landscapes (i.e., with large amounts of habitat; Fig. 3); an assumption supported by work reviewed by Andrén (1994) and Villard and Metzger (2014). Cases where site values (FSHC) are equal to region-based values (FSC) indicate that all fragmented species in the area potentially use that site (points a, b, and c along the diagonal line in Fig. 3). The conservation implication of such cases is that care should be taken when affecting the spatial configuration of patches 
encompassing those cells, and thus it may be important to design landscapes or conservation actions around them. Furthermore, when all species are weighted equally, the sizes of values at sites (cells) with ratios close to one reflect the relevance of the sites in the context of the whole study extent: relatively small values reflect little importance of a site; relatively moderate values reflect local importance; and relatively large values reflect importance at the scale of the entire study area ("global importance"; Fig. 3).

Another informative realm of the parameter space is where site values are low but landscape values are high (point $d$ in Fig. 3). Those cases indicate that a site is located in a fragmentation hotspot, but is not habitat for the fragmented species. In such cases, if patch configuration is truly not important in non-fragmented landscapes, then there could be a case for converting sites at those grid cells to something of benefit to

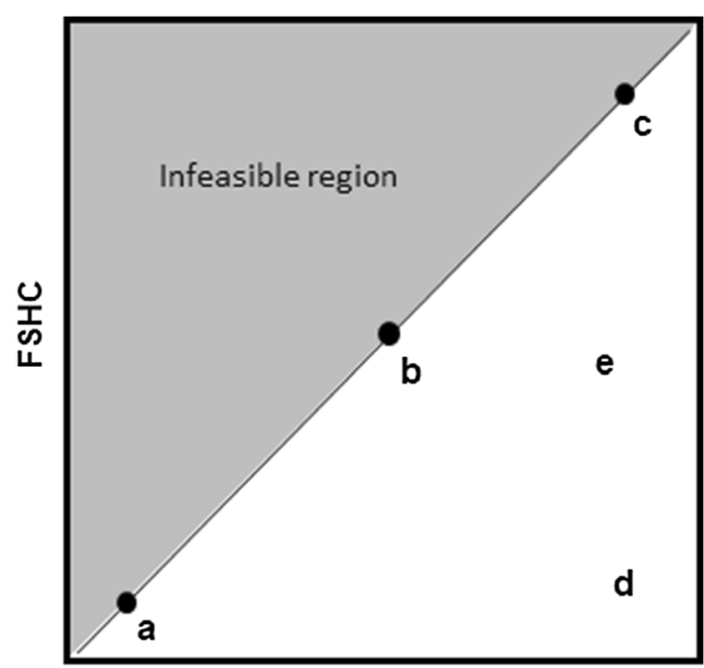

FSC

Fig. 3 The parameter space between fragmented species count (FSC) and fragmented species-habitat count (FSHC). Each site (grid cell) in the study area has a value for each index, so each site has a location within the parameter space. A site's location in the parameter space has implications for landscape conservation actions: the configuration of patches involving a site should be maintained when they are near or along the diagonal line, and doing so is important for (a) a small, (b) a moderate, and (c) a large number of study species for the study region. Sites in location (d) are not habitat for fragmented species but exist within fragmentation hotspots and, thus, may be candidates for conversion for the benefit of fragmented species in the area. Conservation implications are uncertain in areas where values of both indices are moderate, such as (e) fragmented species in the area while offsetting the loss elsewhere as necessary, whereby habitat amount is not significantly altered for any species. Unfortunately, these cases represent extremes, and combinations of moderate values would be more difficult to interpret. For example, were a site in a highly fragmented landscape but with a moderate FSHC value, the implications would be uncertain as they fall between opposing actions: designing a landscape or conservation action around it or considering the conversion of it to something that benefits fragmented species (point $\mathrm{e}$ in Fig. 3).

To demonstrate this type of application for conservation, I mapped areas where habitat configuration is of high and low importance in the study region (grid cells falling in regions a-d in Fig. 3). I identified sites as high importance where FSHC was greater than $95 \%$ of FSC because index values were very similar in those locations. I defined locations where configuration was of low importance as those locations where grid cells were in a region of fragmentation for more than 24 species but were not habitat for any fragmented species. I also explored the FSC-FSHC pairs that occurred in the study area for the 40 study species by recording FSC and FSHC values at 100,000 sample points that I chose at random from within the study area.

The sample of FSC-FSHC value pairs revealed FSHC values that were relatively high, moderate, and low for all but the largest FSC values (Fig. 4a). Pairs with near-equal values occurred, but not at extreme low or high FSC values (i.e., areas a and c in Figs. 3, 4a). The majority of value pairs, however, had relatively low FSHC values and pairs of similar FSHC and FSC values were uncommon (Fig. 4b).

Areas where habitat configuration was of high importance (i.e., where FSHC was nearly equal to FSC) primarily occurred in the western half of the study region along rivers and streams (Fig. 4c), and those grid cells were distributed in small, linear clusters along water features. Between 6 and 14 species were fragmented in the areas where those cells occurred. The importance of habitat configuration in riparian areas suggests that when considering potential conservation actions in the study area, such as the establishment of coarsely delineated corridors, it would be important to investigate and account for the role of riparian corridors in providing habitat connectivity for fragmented species. 
Areas where habitat configuration was of low importance were primarily located throughout the central and southern portions of the study area (Fig. 4c). Those areas included upland portions of foothills and mountains, riversides, urbanized areas, and agricultural fields. The next step in this type of application would be to investigate the landscapes surrounding the areas identified as having high importance of habitat configuration, as well as the ecologies, distributions, vulnerabilities, and conservation priority rankings of the fragmented species inhabiting those sites.

\section{Discussion}

The conceptual model for multispecies landscape pattern indices detailed here can be used to characterize spatial patterns in biodiversity in novel ways that are informative and provide useful context for landscape planning questions. While the spatial patterns of fragmentation in the example presented above may be unsurprising to some (i.e., fragmentation was high along streams and in areas with suburban development), the example demonstrates the way in which the conceptual model can be used to quantify and map landscape patterns with a broader view than is employed with single-species approaches. Those quantifications can have further utility under additional assumptions about landscape patterns and ecological processes, such as fragmentation thresholds and the importance of habitat amount versus configuration. Of course, implementation in real-life could be more complicated and thus application of the model would need to be tailored to specific cases, the relevance of assumptions assessed, and sensitivities explored. Below are some notable points of interest regarding the indices and the model more generally.

The primary requirements for reliable applications of the indices are knowledge of (1) the characteristic scales at which species perceive, interact with, and respond to their environments; (2) accurate models of the spatial distributions of habitat for individual species; and (3) the nature of species' responses to landscapes structure. Those requirements may necessitate research on movement patterns, environmental preferences, and population dynamics of the study species, ideally throughout their ranges. Research on the movements and environmental preferences of
Fig. 4 Summary of FSC and FSHC value pairs from 100,000 randomly selected sites within the example study area; a value pairs of FSHC and FSC; $\mathbf{b}$ the density of value pairs in regions of the parameter space; and $\mathbf{c}$ a map of the importance of habitat configuration created by applying concepts from Fig. 3 to the study area. In c, value pairs that fell in the area labeled " $\mathrm{d}$ " in Fig. 3 were mapped as areas where landscape configuration is of low importance. Areas with high importance of configuration correspond to regions near a, b, and c in Fig. 3, and are weighted according to the FSC values. High importance grid cells were not visible at large map scales because their spatial distribution was a scattered collection of thin, linear patches. Therefore, I aggregated their cell size by a factor of 30 to make them visible on the map. Basemap sources were National Geographic, Esri, DeLorme, HERE, UNEP-WCMC, USGS, NASA, ESA, METI, NRCAN, GEBCO, NOAA, and iPC

individual species could facilitate the development of new habitat models or evaluation of existing ones by revealing the appropriate spatial scales for models (Wiens 1989), as well as which environmental variables can be used to reliably predict where habitat exists. Research on the population dynamics of species could employ spatially-explicit population models capable of assessing the importance of landscape predictors to examine relationships between population vital rates and landscape structure (Dunning et al. 1995). In some cases, models of species abundance or occupancy may suffice (Blevins and With 2011; Forcey et al. 2015).

Several sensitivities should be considered and preferably explored before basing conservation decisions upon CHA, FSC, and FSHC. One, the species list used for analyses will influence the results and should therefore be selected to match a conservation or assessment project's objectives. The indices may be most informative when applied to lists of species of conservation concern, non-generalists, or species known to be responsive to fragmentation. Two, the spatial extent of analyses will influence results when relative measures are employed, such as FSC hot- or coldspots that are identified with a percentile threshold approach, such as the one used by McKerrow et al. (2018), because the spatial extent will influence the frequency distributions of grid cell values. Three, $\mathrm{CHA}$, FSC, and FSHC values are sensitive to errors in the underlying data (Frazier and Kedron 2017), particularly the habitat maps. Important types of error include commission rates, omission rates, spatial pattern error, and scale. Commission and omission 

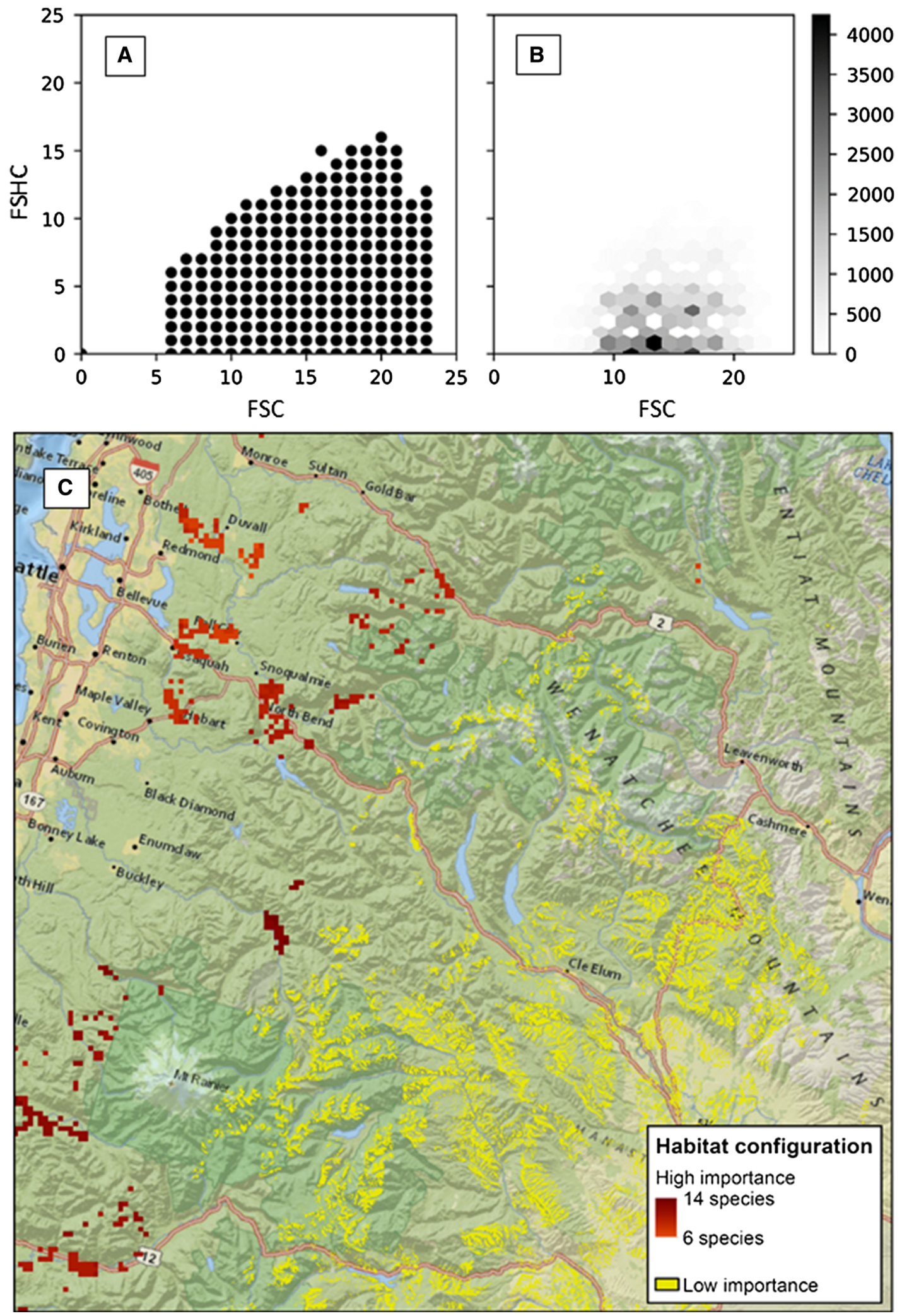
errors in habitat maps could result from mapping the right amount of habitat on the landscape but in the wrong places or spatial patterns. Errors in CHA, FSC, and FSHC would be unpredictable in cases where predicted habitat amounts are accurate but the spatial pattern is not. Commission and omission errors could also arise when models overestimate (commission) or underestimate (omission) the amount of habitat. Overestimates of habitat amount would contribute to underestimates of fragmentation (i.e., biasing FSC and FSHC low), potentially causing a failure to identify all places where habitat configuration is important. Underestimates of habitat amount could cause overestimates of fragmentation and erroneous identification of fragmentation hotspots. Finally, scale errors could entail biases in estimates of species' scales of effect or mismatches between the resolution of data used in models and the resolution at which patches of a species' habitat can be accurately delineated. The model requires that datasets have the same spatial resolutions (i.e., grain), and, therefore, maps must be resampled to a common resolution if the user must employ habitat maps with different native resolutions. Analyses would ideally be conducted at the minimum resolution required to map habitat for all study species in order to minimize the influence of mapping errors. Resampling habitat maps to finer spatial resolutions that nest within the coarser ones would not change the scale of the information represented by the maps, but resampling to a coarser resolutions would.

In some cases, there may be enough data on species of interest to develop more sophisticated or speciesspecific fragmentation thresholds, which could improve the indices. Tailoring the threshold employed to individual species-location combinations by investigating thresholds for individual species within subregions as opposed to the entire study area would be ideal, because doing so could remove more nonfragmented habitat per species and reduce overestimates of the importance of configuration at the multispecies level (Villard and Metzger 2014). Investigations of fragmentation thresholds have generally suggested that configuration is most important at intermediate levels of habitat amount (Andrén 1994; Flather et al. 2002; Freemark et al. 2002; Noon and Dale 2002; Villard and Metzger 2014). However, in some cases, configuration may remain unimportant at all levels of habitat amount. For example, Betts et al. (2006) failed to find any effects of configuration on
Blackburnian Warblers (Setophaga fusca) in the Greater Fundy Ecosystem, New Brunswick, Canada. In addition to empirical studies like that of Betts et al. (2006), spatially-explicit population or simulation models built with information on species' habitat and dispersal abilities can be used to identify fragmentation thresholds. Such models can assess species' responses to patch configuration along gradients of habitat amounts and locate change points in the importance of patch configuration (Fahrig 1997; King and With 2002).

Informative extensions of the indices may also be possible. One, additional utility may be gained by weighting region of fragmentation and fragmented habitat maps (Fig. 1c, d), according to criteria such as species rarity, vulnerability, or conservation priority. For the demonstration, I weighted all species equally. Weights could also be applied according to the influence of or response to fragmentation on local populations, if those are determined to be species- or location-specific. Two, changes in habitat amounts and configurations over time could be examined to incorporate temporal aspects of spatial pattern, which are also relevant in conservation applications (Gustafson 1998). Three, as with all models, there would be great value in empirically testing the characterizations of landscapes obtained with the indices and in quantifying the uncertainty around values.

There are also a few aspects of the broader conceptual model (i.e., aggregating single-species measures of spatial patterns in habitat distribution) which could be developed further or refined for some applications. First, pattern indices other than habitat amount may produce more informative indices in some cases. It is possible that measures of structural connectivity and edge effects, as they relate to population growth and persistence, could be bases for variations on the indices. I employed habitat amount as the foundation for the indices because it is a known landscape predictor of local population processes (Fahrig 2013; Villard and Metzger 2014). Even better would be the use of functional connectivity indices, which would more directly quantify how the landscape within a neighborhood facilitates population processes (Fardila et al. 2017).

In addition, the species- and location-specific natures of habitat definitions and scales of effect suggest that those landscape pattern indices that are optimal for quantifying landscape structure might also 
be species- and location-specific. Just as habitat preferences and scales of effect are unique to individual species, the common shapes and configurations of habitat patches may be unique or variations on common patterns. For example, the shapes and configurations of stream salamander habitat patches would be expected to mirror the spatial patterns of stream networks. The distributions of birds restricted to dry forests might reflect the shapes and configurations of ridges and south-facing slopes. That dimension of uniqueness may influence the appropriateness of particular indices for describing landscape-level influences on local populations of a particular species. It would be valuable to assess how universal the relevance of common landscape pattern indices is across taxa or guilds.

A second valuable refinement would be to move to a more sophisticated spatial model of species' habitats. The patch-matrix model upon which the habitat maps were based have shortcoming that have been described by Fischer and Lindenmayer (2007) and others (Fahrig 2013; Brudvig et al. 2017). In general, they do not accurately reflect the spatial complexities and ecological gradients that occur in nature (Haila 2002; Didham et al. 2011; Frazier and Kedron 2017) where habitat quality, patch effects, matrix hostility, and other factors exist as continuums rather than binary states (Taylor et al. 1993; Fahrig 2001; Fischer and Lindenmayer 2007). Therefore, continuum or hybrid patch-matrix continuum models could provide improvements to the accuracy of fragmentation science and landscape conservation (Brudvig et al. 2017). On the other hand, patch-matrix models can be sufficient in many cases because they match the level of detail involved in many conservation questions, such as 'how much habitat exists for a species?', 'where is it?', and 'how fragmented is it?'

Finally, better scale of effect estimates and neighborhood delineation may be possible in some cases. There is much to learn about species' movement ecologies and, thus, landscape effects on local populations. Key aspects of this topic are the distances at which landscape structure influences populations (i.e., domains in scales of effect) and the nature of those relationships when they exist. Although the proxies for scale of effect that I used were rough, it is possible that they were within the domains at which habitat amount effects are greatest (Wheatley 2010). However, Tittler et al. (2009) found evidence that mark-recapture data, a common basis for estimating dispersal distances, greatly underestimated dispersal distances. Delineations of neighborhoods could also be refined by accounting for landscape features around each site (grid cell) that impede movement by species, such as interstates, ridgelines, and large water bodies. Those refinements could improve the accuracy of multispecies indices and would require research into species' movement patterns and abilities as well as methods for identifying and mapping species-specific barriers to movements.

The basic challenge of landscape conservation is a formidable one: maximize the ability to influence population persistence for species of interest along with ecosystem function and resiliency through targeted landscape change. The path to success is likely more feasible with diverse suites of decision support tools (i.e., models and indices) than with a single all-encompassing index. Thus, CHA, FSC, and FSHC would be most valuable when used in conjunction with other biodiversity indices such as species richness, rarity, vulnerability, and habitat quality to frame, characterize, and examine landscape problems. This is true in part because landscape effects on local populations are often relatively mild (Fahrig 2001; Cushman and McGarigal 2004; Betts et al. 2006). Nevertheless, multispecies indices can provide views of landscapes that are rooted in the uniqueness of individual species and the spatial patterns of natural and anthropogenic landscape features. Such views could broaden our understanding of the context surrounding conservation actions and shed light on the complexity of habitat conservation challenges and the potential for tradeoffs involved in their solutions.

Acknowledgements Special thanks to Kurt Riitters, Jennifer Costanza, James Wickham, and anonymous reviewers for comments that greatly improved the manuscript; Matthew Rubino for assistance compiling scale of effect estimates; and Alexa McKerrow, Steve Williams, and Jaime Collazo for general support. Funding was provided by the U.S. Geological Survey Science Analytics and Synthesis's Biogeographic Characterization Branch through the North Carolina Cooperative Fish and Wildlife Research Unit Research Work Order 222. Any use of trade, product or firm names is for descriptive purposes only and does not imply endorsement by the U.S. Government.

Open Access This article is distributed under the terms of the Creative Commons Attribution 4.0 International License (http:// creativecommons.org/licenses/by/4.0/), which permits unrestricted use, distribution, and reproduction in any medium, 
provided you give appropriate credit to the original author(s) and the source, provide a link to the Creative Commons license, and indicate if changes were made.

Data availability The datasets analyzed during the current study are available in the ScienceBase catalog, and persistent web links for them are listed in Supplemental Materials. The datasets generated are available from the corresponding author on reasonable request.

\section{References}

Addicott JF, Aho JM, Antolin MF, Padilla DK, Richardson JS, Soluk DA (1987) Ecological neighborhoods: scaling environmental patterns. Oikos 49(3):340-346

Andrén H (1994) Effects of habitat fragmentation on birds and mammals in landscapes with different proportions of suitable habitat: a review. Oikos 71(3):355-366

Araújo MB, Anderson RP, Barbosa AM, Beale CM, Dormann CF, Early R, Garcia RA, Guisan A, Maiorano L, Naimi B, O'Hara RB, Zimmerman NE, Rahbek C (2019) Standards for distribution models in biodiversity assessments. Sci Adv 5(1):eaat 4858

Belote RT, Dietz MS, McRae BH, Theobald DM, McClure ML, Irwin GH, McKinley PS, Gage JA, Aplet GH (2016) Identifying corridors among large protected areas in the United States. PLoS ONE 11(4):e0154223

Betts MG, Forbes GJ, Diamond AW, Taylor PD (2006) Independent effects of fragmentation on forest songbirds: an organism-based approach. Ecol Appl 16(3):1076-1089

Blevins E, With KA (2011) Landscape context matters: local habitat and landscape effects on the abundance and patch occupancy of collared lizards in managed grasslands. Landscape Ecol 26:837-850

Brudvig LA, Leroux SJ, Albert CH, Bruna EM, Davies KF, Ewers RM, Levey DJ, Pardini R, Resasco J (2017) Evaluating conceptual models of landscape change. Ecography 40:74-84

Cushman SA, McGarigal K (2004) Hierarchical analysis of forest bird species-environment relationships in the Oregon coast range. Ecol Appl 14(4):1090-1105

Didham R, Kapos V, Ewers RM (2011) Rethinking the conceptual foundations of habitat fragmentation research. Oikos 121:161-170

Dunning JB, Stewart DJ, Danielson BJ, Noon BR, Root TL, Lamberson RH, Stevens EE (1995) Spatially explicit population models: current forms and future uses. Ecol Appl 5(1):3-11

ESRI (2016) ArcGIS desktop: release 10.4. Environmental Systems Research Institute, Redlands

Fahrig L (1997) Relative effects of habitat loss and fragmentation on population extinction. J Wildl Manage 61(3):603-610

Fahrig L (2001) How much habitat is enough? Biol Conserv 100:65-74

Fahrig L (2003) Effects of habitat fragmentation on biodiversity. Annu Rev Ecol Evol Syst 34:487-515
Fahrig L (2013) Rethinking patch size and isolation effects: the habitat amount hypothesis. J Biogeogr 40:1649-1663

Fardila D, Kelly LT, Moore JL, McCarthy MA (2017) A systematic review reveals changes in where and how we have studied habitat loss and fragmentation over 20 years. Biol Conserv 212:130-138

Fischer J, Lindenmayer DB (2007) Landscape modification and habitat fragmentation: a synthesis. Glob Ecol Biogeogr 16:265-280

Flather CH, Bevers M, Hof J (2002) Prescribing habitat layouts: analysis of optimal placement for landscape planning. In: Gutzwiller K (ed) Applying landscape ecology in biological conservation. Springer, New York, pp 429-453

Forcey G, Thogmartin WE, Linz GM, Mckann PC, Crimmins SM (2015) Spatially explicit modeling of blackbird abundance in the Prairie Pothole region. J Wildl Manage 79(6):1022-1033

Franklin J (2009) Mapping species distributions: spatial inference and prediction. Cambridge University Press, Cambridge

Frazier AE, Kedron P (2017) Landscape metrics: past progress and future directions. Curr Landsc Ecol Rep 2017(2):63-72

Freemark K, Bert D, Villard MA (2002) Patch-, landscape-, and regional-scale effects on biota. In: Gutzwiller $\mathrm{K}$ (ed) Applying landscape ecology in biological conservation. Springer, New York, pp 58-83

Gustafson EJ (1998) Quantifying landscape spatial pattern: what is the state of the art? Ecosystems 1998(1):143-156

Haddad NM, Gonzalez A, Brudvig LA, Burt MA, Levey DJ, Damschen EI (2017) Experimental evidence does not support the habitat amount hypothesis. Ecography 40:48-55

Haila Y (2002) A conceptual geneology of fragmentation research: from island biogeography to landscape ecology. Ecol Appl 12(2):321-334

Hall LS, Krausman PR, Morrison ML (1997) The habitat concept and a plea for standard terminology. Wildl Soc Bull 25(1):173-182

Huxel GR, Hastings A (1999) Habitat loss, fragmentation, and restoration. Restor Ecol 7(3):309-315

Jackson HB, Fahrig L (2012) What size is a biologically relevant landscape? Landscape Ecol 27:929-941

King AW, With KA (2002) Dispersal success on spatially structured landscapes: when do spatial pattern and dispersal behavior really matter? Ecol Model 147(1):23-39

Lindenmayer DB, Fischer J (2006) Tackling the habitat fragmentation panchreston. Trends Ecol Evol. https://doi.org/ 10.1016/j.tree.2006.11.006

Martin AE, Fahrig L (2012) Measuring and selecting scales of effect for landscape predictors in species-habitat models. Ecol Appl 22(8):2277-2292

McGarigal K (2015) FRAGSTATS documentation. http://www. umass.edu/landeco/research/fragstats/documents/ fragstats.help.4.2.pdf

McKerrow AJ, Tarr NM, Rubino MJ, Williams SG (2018) Patterns of species richness hotspots and estimates of their protection are sensitive to spatial resolution. Divers Distrib 24(10):1464-1477 
McKinney W, PyData Development Team (2018) Pandas: powerful Python data analysis toolkit, release 0.23.0. https://pandas.pydata.org. Accessed 1 Apr 2018

NatureServe (2018) NatureServe explorer: an online encyclopedia of life [web application]. Version 7.1. NatureServe, Arlington. http://explorer.natureserve.org. Accessed 1 Mar 2018

Noon BR, Dale VH (2002) Broad-scale ecological science and its application. In: Gutzwiller K (ed) Applying landscape ecology in biological conservation. Springer, New York, pp 34-52

Noon BR, McKelvey KS, Dickson BG (2009) Multispecies conservation planning on U.S. federal lands. In: Millspaugh JJ, Thompson RR III (eds) Models for planning wildlife conservation in large landscapes. Academic Press, Cambrigde, pp 51-83

Python Software Foundation (2010) Python language reference, version 2.7. http://www.python.org. Accessed 1 Apr 2018

Taylor PD, Fahrig L, Henein K, Merriam G (1993) Connectivity is a vital element of landscape structure. Oikos 68(3):571-573

Tittler R, Villard M, Fahrig L (2009) How far do songbirds disperse? Ecography 32(6):1051-1061
U.S. Geological Survey: Gap Analysis Project (2018) U.S. Geological Survey: Gap Analysis Project species habitat maps CONUS_2001: U.S. Geological Survey data release. https://doi.org/10.5066/F7V122T2. Accessed 8 Aug 2018

Villard MA, Metzger JP (2014) Beyond the fragmentation debate: a conceptual model to predict when habitat configuration really matters. J Appl Ecol 51:309-318

Vos CC, Baveco H, Grashof-Bokdam CJ (2002) Corridors and species dispersal. In: Gutzwiller K (ed) Applying landscape ecology in biological conservation. Springer, New York, pp 84-104

Wheatley M (2010) Domains of scale in forest-landscape metrics: implications for species-habitat modeling. Acta Oecol 36:259-267

Wiens JA (1989) Spatial scaling in ecology. Funct Ecol 3(4):385-397

Publisher's Note Springer Nature remains neutral with regard to jurisdictional claims in published maps and institutional affiliations. 